PAPER

\title{
Clinical features and long term outcome of epilepsy in periventricular nodular heterotopia. Simple compared with plus forms
}

\author{
G d'Orsi, P Tinuper, F Bisulli, A Zaniboni, B Bernardi, G Rubboli, R Riva, R Michelucci, L Volpi, \\ C A Tassinari, A Baruzzi
}

J Neurol Neurosurg Psychiatry 2004;75:873-878. doi: 10.1136/jnnp.2003.024315

\begin{abstract}
See end of article for authors' affiliations

...................

Correspondence to: Professor P Tinuper, Department of Neurological Sciences, University of Bologna, Via Ugo Foscolo 7, 40123 Bologna, Italy; tinuper@neuro.unibo.it
\end{abstract}

Received 24 July 2003 Revised

25 September 2003

Accepted 4 October 2003

\begin{abstract}
Objectives: Little is known about the long term outcome of patients with periventricular nodular heterotopia (PNH) and epilepsy, particularly the course of seizures. This study investigated the electroclinical and prognostic features of 16 patients with $\mathrm{PNH}$.

Methods: Of 120 patients with epilepsy and malformations of cortical development, 16 had PNH. Of these, eight patients had periventricular nodules only (simple PNH) and eight also presented with other cortical or cerebral malformations (subcortical heterotopia; polymicrogyria; focal dysplasia; schizencephaly; cortical infolding; agenesis of the corpus callosum; mega cisterna magna and cerebellar atrophy) (PNH plus). All patients underwent clinical, neurophysiological, and MRI investigation. The mean follow up was 17.3 years $(2-40$ years).

Results: Two electroclinical patterns emerged: (1) The first pattern, associated with simple PNH, was characterised by normal intelligence and seizures, usually partial, which began during the second decade of life. The seizures never became frequent and tended to disappear or become very rare. The EEG showed focal abnormalities. (2) The second pattern, associated with PNH plus, was characterised by mental retardation and seizures that began during the first decade of life. The seizures were very frequent in most cases and sudden drops were observed in six patients. Seizures were medically refractory in four patients. The EEG showed focal and bisynchronous abnormalities.

Conclusions: Two groups of PNH patients with different electroclinical and neuroradiological features can be identified after a long term follow up. The presence of other types of cortical or cerebral malformations, in addition to periventricular nodules, determines a poor prognosis.
\end{abstract}

$\mathrm{P}$ eriventricular (subependymal) nodular heterotopia (PNH) are malformations of cortical development (MCD) characterised by single or multiple nodules of grey matter adjacent to the lateral ventricular walls. ${ }^{1}$ The nodules usually bulge into the ventricle and range in size from small, discrete neuronal clusters to large multinodular conglomerates. According to anatomical-radiological classifications of cortical developmental abnormalities, ${ }^{23}$ $\mathrm{PNH}$ may present as malformations attributable to a generalised abnormal cortical development or in focal or multifocal abnormalities. Generalised $\mathrm{PNH}$ consists of bilateral contiguous nodules creating an irregular bumpy surface lining the ventricular wall. Focal or multifocal PNH is considered a localised abnormality with multiple but not contiguous nodules. Both generalised and localised nodular heterotopia are attributable to abnormal neuronal migration $^{2}$ and may be isolated or associated with other cortical and brain malformations. PNH are attributable to a group of neuroblasts that seems incapable of the usual radial and tangential migration from the ventricular zone during cortical development. When there is a primary, limited, and pure deficit in neuronal migration onset, the remaining neuroblasts may migrate normally to form the regular six layered cortex and PNH only appear. When the ongoing process of migration or of the later stage of neuronal migration and cortical organisation are also impaired, subcortical heterotopia or polymicrogyria and schizencephaly may develop with $\mathrm{PNH}^{4-13}$ Lastly, other brain developmental abnormalities such as agenesis of the corpus callosum, hydrocephalus, mega cisterna magna, and cerebellar hypoplasia may also be associated with PNH. ${ }^{14-17}$

High resolution magnetic resonance imaging (MRI) has revolutionised the study of MCD by showing how important these conditions are as a cause of epilepsy, contributing to a greater understanding of the pathophysiology and recent classification of such malformations. ${ }^{18}$ MRI is the best imaging modality to disclose $\mathrm{PNH}$ and describe the morphology, extension, and boundaries of the malformation and may display associated cortical dysplasias or other brain malformations. MRI features of PNH are sufficient to identify it as a distinct neuronal migration disorder. Nevertheless, while many recent papers have described the advances of neuroradiological aspects of cortical malformations, ${ }^{19}{ }^{20}$ few studies have investigated the clinical, syndromic, and, more importantly, prognostic and long term follow $u^{21}{ }^{22}$ of patients with these malformations.

We investigated the clinical, neurophysiological, and neuroimaging features of 16 patients with $\mathrm{PNH}$, focusing on the course and prognosis of epilepsy in this group of cortical malformations.

To our knowledge, this is the first long term follow up monitoring the course of epilepsy in $\mathrm{PNH}$ patients.

\section{METHODS}

In a population of 120 patients with epilepsy and MCD diagnosed at our institutions (Department of Neurological

Abbreviations: $\mathrm{PNH}$, periventricular nodular heterotopia; $\mathrm{MCD}$, malformations of cortical development 
Sciences, University of Bologna, Bologna and Department of Neurosciences, Bellaria Hospital, Bologna, Italy), we found $16 \mathrm{PNH}$ patients with single or multiple but not contiguous nodules. Patients comprised eight women and eight men, aged 15-48 years (mean 29). The mean follow up was 17.3 years, with a minimum of two years and a maximum of 40 years from the onset of epilepsy. The patients were followed up by quarterly or six monthly clinical examination and were re-interviewed and re-examined with their relatives. We collected clinical data on the family history (febrile convulsions, epilepsy, mental retardation, spontaneous miscarriages, and neurological disease), antenatal and birth history focusing on prenatal or perinatal risk factors, developmental milestones, age at seizure onset, seizure description and course, neurological status with neuropsychological assessment, and drug response. Several serial EEGs were recorded in wakefulness and sleep with the 10-20 International System of electrode positioning. One case with intractable epilepsy (patient 16) underwent surgical treatment and was also recorded by means of video EEG monitoring with multiple depth electrodes.

MRI was performed with high field strength (1.5-Tesla System). Protocol MRI studies for epilepsy included four sequences. Axial long TR SE or FSE sequences to obtain $\mathrm{PD}$ or $\mathrm{T} 2$ weighted images (PD/T2 WI), 3 to $5 \mathrm{~mm}$ thick. Tl weighted images can provide high contrast resolution between grey and white matter, and high spatial resolution. For this reason, spoiled gradient recalled echo (SPGR, RF-FAST) volume TIWI with sagittal partitions of about $1.2-1.5 \mathrm{~mm}$ were included. This 3D TIWI sequence permits reformatting in any orientation of the dataset. To optimise grey/white matter contrast we also used fast inversion recovery (FSE-IR) images on coronal planes ( $3 \mathrm{~mm}$ thickness). Fluid attenuated inversion recovery (FLAIR) sequences $(3-4 \mathrm{~mm}$ ) with heavy T2WI and suppression of the CSF signal were used on coronal planes to rule out abnormalities other than cortical malformations.

All images were evaluated by the same neuroradiologist (BB), experienced in the imaging of epilepsy and aware of the clinical history of each patient.

Statistical analysis was performed by Mann-Whitney rank sum test or Fisher exact test when appropriate.

Patients with PNH were classified into two groups: the first, simple PNH, included patients with nodules located only along lateral ventricles, without other cortical and/or cerebral malformations (eight patients); the second, PNH plus, patients with periventricular nodules associated with other cortical and/or cerebral malformations (eight patients).

\section{RESULTS}

Table 1 summarises clinical features and table 2 EEG and MRI findings.

Sex and age of patients were not statistically significant between the two groups (27.6 (2.8) compared with 30.6 (10.05) years, simple PNH patients compared with PNH plus patients respectively). Seizure onset was significantly earlier in the plus PNH group (mean 4.2 (4.7) years) with respect to simple PNH group $(19.2(1.6)$ years $)(p<0.001)$. Neurological deficits were more common in the $\mathrm{PNH}$ plus group $(p=0.041)$. Drop attacks were experienced only in PNH plus patients $(p<0.001)$. Seizure frequency was significantly higher in the $\mathrm{PNH}$ plus group (median 98 seizures/year) than the other group (median six seizures/year) $(p<0.002)$.

We describe in detail the instrumental and clinical features of the two groups.

\section{Group 1: simple PNH}

\section{Clinical features}

The simple group included eight patients, five women and three men, ranging in age from 24 to 31 years (median 27.6). Family epilepsy history was negative in all patients. Patient 6 had a family history positive for migraine. Perinatal risk factors were reported in patient 5 with a threatened abortion at the first month of pregnancy and in patient 6 with preterm delivery secondary to Rh incompatibility. All patients had normal acquisition of early developmental milestones and showed normal intelligence with a normal full scale intelligence quotient (IQ). No patients had neurological deficit or dysmorphisms.

\section{Seizure history and outcome}

Median age at seizure onset was 19.2 years (range 17-22). Seizure types were partial in two patients and partial with secondary generalisation in six patients. The clinical semeiology of the seizures, described by patients and witnesses, suggested a temporal onset in five patients, while an extratemporal onset (frontal and parietal) was assumed in the others. The mean follow up was 8.3 years, with a minimum of two years and a maximum of 14 years from the onset of epilepsy. The outcome and evolution of epilepsy were similar in all patients. At onset, the seizures occurred once or several times a year. During the course of epilepsy, patients usually maintained the comparatively low frequency of seizures with rare periods of monthly episodes. Over the years, the number of seizures tended to decrease. Only three cases (patients 2, 4, and 7) reported seizures several times a month, but they also showed a progressive reduction in the number of seizures from year to year, confirming the comparatively benign course. The seizures were partially controlled (reduction of seizures frequency $<50 \%$ ) in three cases (patients 1,3 , and 4 ), who received a combination of two to three drugs. In two other patients (patients 7 and 8 ), the seizures improved (reduction of seizures frequency $>50 \%$ ) with one or two drugs. Three cases (patients 2, 5, and 6) became seizure free.

\section{EEG findings}

Wakeful interictal EEG recordings showed a normal background activity in all patients. Focal abnormalities, nonspecific ( $\theta$ activity) or epileptiform, were present in all recordings except those in patients 6 and 8. In all cases, the lateralisation of abnormalities was congruous with the side of the nodules. The patients with bilateral nodules showed normal electrical activity (patients 6 and 8 ) or asynchronous sharp and slow waves (patient 7). Sleep patterns were preserved in all cases and in one case (patient 2) sleep disclosed paroxysmal abnormalities not evident on awake EEG. In two cases (patients 4 and 5), we recorded seizures having an onset congruous with the side of the nodules. No patient showed photic driving or other EEG changes during photic stimulation.

\section{MRI findings}

Well defined small nodules of heterotopic grey matter appeared isointense with normal grey matter on all imaging sequences. The surrounding white matter and the overlying cortex were macroscopically normal and the gyral pattern did not show abnormalities (fig 1, Al-A2). The nodules could be single (patients 1 and 3 ) or multiple, not contiguous, localised along the walls of the lateral ventricles. In particular, patients 1 to 5 showed nodules localised along the lateral walls of only one ventricle (patients 1 and 3 along the frontal horn; patients 2 and 4 along the temporal horn, only patient 5 along the occipital horn). By contrast, cases 6 (as shown in the example of fig $1, \mathrm{Al}-\mathrm{A} 2$ ), 7, and 8 had bilateral, not contiguous nodules along the outline of both 
Table 1 Clinical features in PNH patients

\begin{tabular}{|c|c|c|c|c|c|c|c|}
\hline & Patient & Age $(y) / \operatorname{sex}$ & Neurological findings* & Age (y) at seizures onset† & Seizures typet & $\begin{array}{l}\text { Seizure frequency } \\
\text { mean (SD) (seizures/ } \\
\text { y) }\end{array}$ & Drug response \\
\hline \multirow[t]{8}{*}{ Simple } & 1 & $24 / F$ & - & 19 & PSG & $3.8(4.4)$ & $<50 \%$ \\
\hline & 2 & $31 / F$ & - & 17 & PSG & $9.8(12.6)$ & SF \\
\hline & 3 & $26 / M$ & - & 19 & PSG & $7.4(5.6)$ & $<50 \%$ \\
\hline & 4 & $29 / M$ & - & 19 & PC & $14.8(17.7)$ & $<50 \%$ \\
\hline & 5 & $28 / M$ & dyslexia & 19 & PSG & $1.2(2.1)$ & SF \\
\hline & 6 & $28 / F$ & - & 21 & PSG & $5.3(5.6)$ & SF \\
\hline & 7 & $31 / F$ & - & 18 & PC & $8.0(17.8)$ & $>50 \%$ \\
\hline & 8 & $24 / F$ & - & 22 & PSG & $3.0(3.5)$ & $>50 \%$ \\
\hline \multirow[t]{8}{*}{ Plus } & 9 & $48 / F$ & - & 14 & PC/DROP & $47.0(33.5)$ & $>50 \%$ \\
\hline & 10 & $27 / M$ & $\begin{array}{l}\text { psychomotor retardation, } \\
\text { behaviour disturbances }\end{array}$ & 9 & PSG/DROP & 199.5 (178.9) & SF \\
\hline & 11 & $33 / M$ & - & 3 & PC/DROP & $117.8(88.8)$ & $>50 \%$ \\
\hline & 12 & $27 / F$ & $\begin{array}{l}\text { psychomotor retardation, } \\
\text { dysmorphisms }\end{array}$ & 2 & $\mathrm{PC}$ & $30.7(78.8)$ & $<50 \%$ \\
\hline & 13 & $23 / M$ & psychomotor retardation & 1 & PS/TON & $6.7(4.9)$ & SF \\
\hline & 14 & $15 / M$ & $\begin{array}{l}\text { psychomotor retardation, } \\
\text { dysmorphisms }\end{array}$ & 1 & TC/DROP & 165.7 (113.2) & $<50 \%$ \\
\hline & 15 & $30 / \mathrm{F}$ & $\begin{array}{l}\text { mild psychomotor } \\
\text { retardation }\end{array}$ & 2 & PS/DROP/TON & $79.3(45.2)$ & $<50 \%$ \\
\hline & 16 & $42 / M$ & $\begin{array}{l}\text { psychomotor retardation, } \\
\text { left hemiparesis }\end{array}$ & 2 & PC/DROP/PSG & $293.3(132.8)$ & $<50 \%$ \\
\hline
\end{tabular}

Simple PNH compared with plus PNH: * $\mathrm{p}=0.041 ; \mathrm{t} p<0.001 ; \neq \mathrm{p}<0.002$. PSG, partial secondarily generalised; PC, complex partial; PS, simple partial; TC, tonic-clonic; TON, tonic; SF, seizures free.

lateral walls. Finally, in patients with a unilateral localisation of the nodules there was a mild preponderance of nodules along the right lateral ventricle (right/left: $3 / 2$ ), whereas they were substantially symmetrical in patients with a bilateral distribution.

\section{Group 2: PNH plus}

Clinical features

This group included eight patients, three women and five men, 15-48 years old (median 30.6 years). Family history was negative for epilepsy in all patients with the exception of case 12 (mother with tonic-clonic seizures after head trauma). Pre-perinatal risk factors were reported in three patients (cases 10, 14, and 16): in two cases (patient 10 and 16), there had been caesarean sections for altered presentation or surgery at the third month of pregnancy for uterine fibroma (patient 10) or prolonged jaundice (Rh incompatibility) during the first days of life (patient 16). Six patients reported retarded acquisition of early developmental milestones, ranging from mild (patient 15 with an IQ of 65) to severe deficit (patient 14 with an IQ not valuable). Patient 10 had behavioural disturbances; two patients had neurological deficits (hemiparesis) or facial dysmorphisms (patients 12 and 16). Finally, patient 14 had a complex clinical picture (facial dysmorphisms, small penis and undescended testes, hypoplastic distal and middle phalanges, obesity, mental retardation, and epilepsy) compatible with a diagnosis of Borjeson-Forssman-Lehmann syndrome. ${ }^{23}$ A kidney malformation (ectopia) was evident in patient 12 .

Table 2 EEG and MRI findings in PNH patients

\begin{tabular}{|c|c|c|c|c|c|c|}
\hline & Patient & EEG focus & SBB & Nodule location & Nodule type & $\begin{array}{l}\text { Other malformations (cortical, cerebral, } \\
\text { and systemic) }\end{array}$ \\
\hline \multirow[t]{8}{*}{ Simple } & 1 & $\mathrm{LT}$ & No & LF horn & unilateral & - \\
\hline & 2 & L-R FT & No & L T horn & unilateral & - \\
\hline & 3 & $\mathrm{RF}$ & No & R F horn & unilateral & - \\
\hline & 4 & R T & No & R T horn & unilateral & - \\
\hline & 5 & R FT & No & $\mathrm{R} O$ horn & unilateral & - \\
\hline & 6 & normal & No & R, L T horns & bilateral symmetric & - \\
\hline & 7 & L-R T & No & R, L T horns & bilateral symmetric & - \\
\hline & 8 & normal & No & R, L T-O horns & bilateral symmetric & - \\
\hline \multirow[t]{8}{*}{ Plus } & 9 & R T & Yes & R T horn & unilateral & $\begin{array}{l}\text { megacisterna magna, cerebellar vermis } \\
\text { hypoplasia, colpocephaly }\end{array}$ \\
\hline & 10 & R T & Yes & R T horn & unilateral & $\begin{array}{l}\text { megacisterna magna, cerebellar vermis } \\
\text { hypoplasia, CC agenesis, R F dysplasia, } \\
\text { R schizencephaly }\end{array}$ \\
\hline & 11 & R T & Yes & R T-O horn & unilateral & $\begin{array}{l}\text { R T-O subcortical heterotopia and cortical } \\
\text { dysplasia }\end{array}$ \\
\hline & 12 & L FT & No & L T horn & unilateral & $\begin{array}{l}\text { L T dysplasia; kidney malformation } \\
\text { (ectopia) }\end{array}$ \\
\hline & 13 & $\mathrm{LT}$ & No & L T horn & unilateral & $\begin{array}{l}\text { hypoplasia CC, multiple F poroencephalic } \\
\text { cysts; L T-P cortical infolding }\end{array}$ \\
\hline & 14 & L-R FT & Yes & R T-O horn & unilateral & CC agenesis, R T dysplasia \\
\hline & 15 & R FT & Yes & R, L T horns & bilateral asymmetric $\mathrm{R}>>\mathrm{L}$ & R F-T dysplasia \\
\hline & 16 & R FT & Yes & R, L T-O horns & bilateral asymmetric $\mathrm{R}>>\mathrm{L}$ & $\begin{array}{l}\text { cortical malformation of T-P junction; } \\
\text { R T-O polymicrogyria }\end{array}$ \\
\hline
\end{tabular}

SBB, secondarily bilateral bisynchrony; L, left; R, right; F, frontal; T temporal; FT, frontotemporal; O, occipital; T-O, temporal-occipital; T-P, temporal-parietal; CC, corpus callosum. 


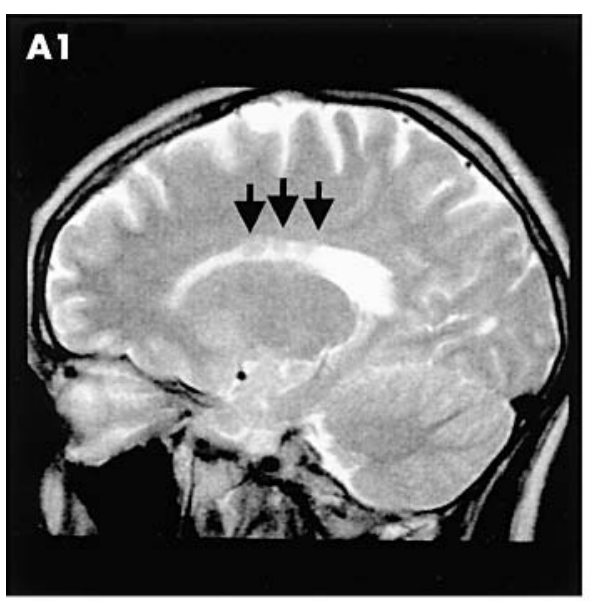

\section{A2}
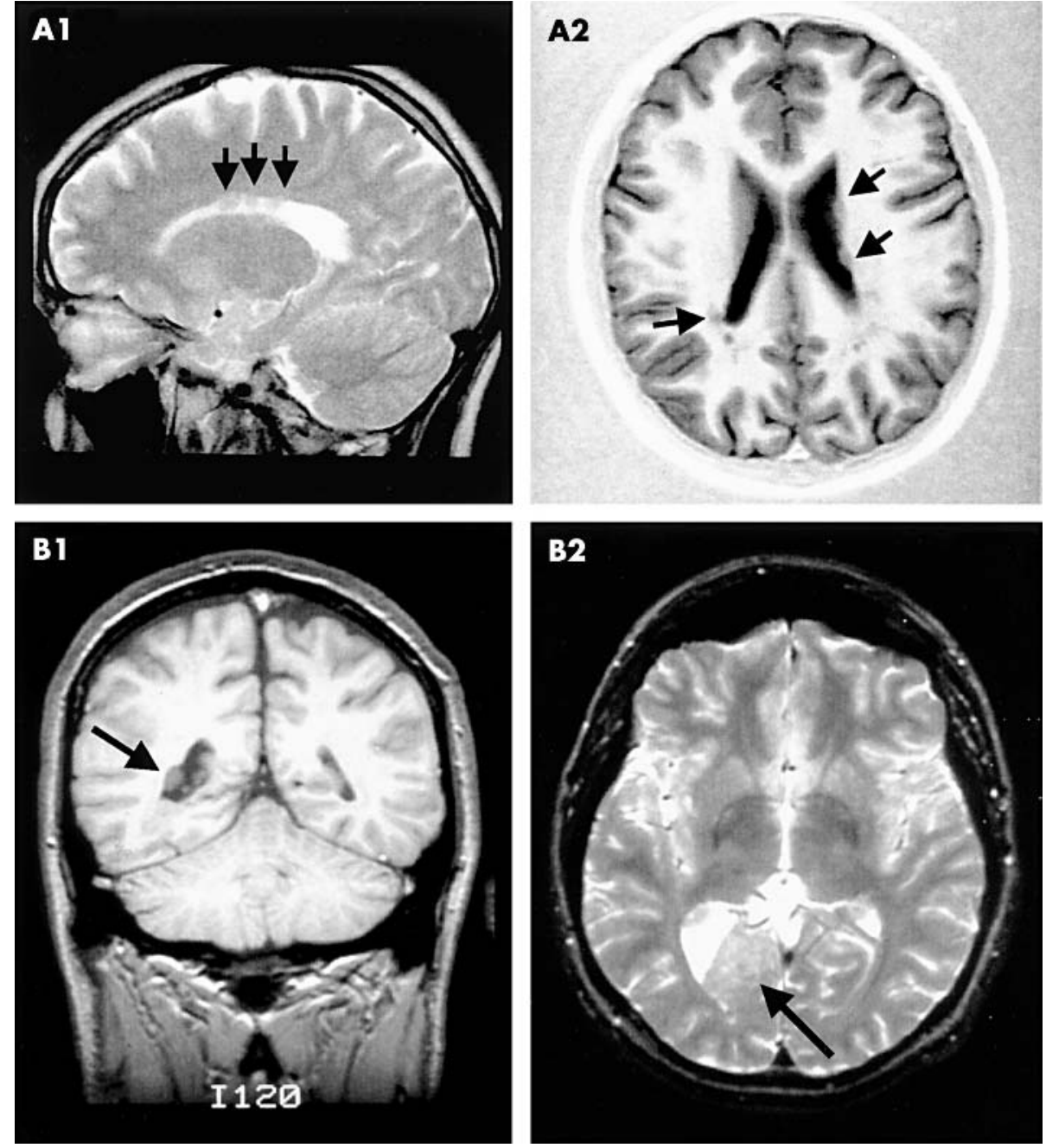

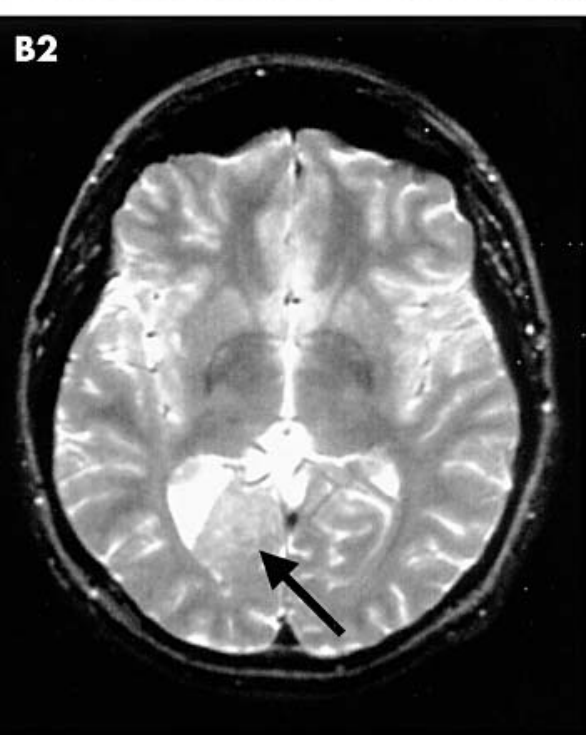

Figure $1 \mathrm{MRI}$. (A1-A2) Patient 6 with simple $\mathrm{PNH},(\mathrm{B} 1-\mathrm{B} 2)$ patient 10 with plus PNH. (A1) Sagittal TSE T2 WI shows multiple periventricular nodules (arrows). The signal from the nodules is homogeneous and consistent with grey matter. (A2) Axial TSE-IR T1 WI shows bilateral, asymmetric isointense nodules along the outline of both lateral ventricular walls (arrows). The overlying cortex is normal. (B2) Axial TSE T2 WI displays subependymal heterotopic grey matter along the posterior part of the floor of the right lateral ventricle, associated with subcortical heterotopia and focal cortical dysplasia. (B1)

Coronal SE TI WI shows a large, single periventricular heterotopic grey matter nodule (arrow) at the level of the right trigone that is enlarged.
Seizure history and outcome

The age at seizure onset showed a median age of 4.25 years (range 1-14). Multiple seizure types were present (simple partial, complex partial, partial secondary generalised, tonic, tonic-clonic); sudden drops were observed in six patients. The mean follow up was 26 years, with a minimum of 14 years and a maximum of 40 years from epilepsy onset. At onset, the seizures were very frequent, occurring daily or pluri-monthly in all patients. During the course of epilepsy, the high frequency was maintained in most cases. The seizures were medically refractory in four cases (patients 12, 14, 15, and $16)$; in patients 9 and 11 , there was a reduction of seizure frequency $>50 \%$. Only two cases (10 and 13 ) had a late reduction in the numbers of episodes even becoming seizure free. Patient 16 continued to have seizures with the usual frequency but intensity and duration was reduced after right partial temporoparietal cortectomy and lesionectomy (polymicrogyria and periventricular heterotopia).

\section{EEG findings}

EEG interictal recordings showed a normal background activity in six patients and diffuse slowing in two cases. Focal abnormalities, non-specific ( $\theta$ activity) or epileptiform, were present in all patients. Bisynchronous discharges were recorded in six patients, in particular in cases with sudden drops. The lateralisation of abnormalities was congruous with the side of nodules. Sleep patterns were preserved in all cases and in patients 11 and 12 sleep enhanced abnormalities present in wake EEG. In two cases (patients 15, 16), we recorded seizures with EEG onset congruous with the side of nodules. The patient who underwent surgical treatment (patient 16) showed interictal and ictal abnormalities in the right temporal region. Stereo EEG recordings showed an epileptogenic zone that included the right middle temporal region as well as temporoparietal and temporo-occipital junction; the occipital part of heterotopia was not involved.

\section{MRI findings}

Subependymal heterotopia were characterised by clusters of grey matter larger than the small nodules present in the simple group. The periventricular nodules were multiple, not contiguous, unilateral, or bilateral, and were localised along the external walls of the lateral ventricles. In particular, patients 9-14 showed unilateral nodules: cases 9, 10, and 12 along the temporal horns; cases 11, 13, and 14 along the temporal and occipital horns. Instead, patients 15 and 16 had bilateral and not contiguous nodules, respectively along the temporal (patient 15) and temporal and occipital horns (patient16). Finally, there was a preponderance of nodules along the right lateral ventricle both in unilateral (right/left: $4 / 2$ ) and bilateral cases. Periventricular nodules were associated with other cortical and cerebral malformations. Four patients showed focal cortical dysplasia (patients 10, 12, $14,15)$, one polymicrogyria (patient 16), one (patient 11) subcortical heterotopia with cortical dysplasia (fig 1, B1-B2), one cerebral cortical infolding and hypoplasia of the corpus callosum (patient 13), one mega cisterna magna with cerebellar hypoplasia (patient 9). Moreover, patients 9, 10, 
13, 14, and 16 also showed other concomitant abnormalities. In particular, patient 9 had also colpocephaly with deformation of the enlarged occipital horns, patient 10 had corpus callosum agenesis and schizencephaly, patient 13 had multiple poroencephalic cysts, patient 14 had corpus callosum agenesis without other abnormalities, patient 16 showed a cortical malformation of temporal-parietal junction.

\section{DISCUSSION}

Like other cortical malformations, $\mathrm{PNH}$ are considered to be associated with developmental delay and epilepsy, but a wide variety and heterogeneity of clinical pictures are often present. $^{515} 24$ Epilepsy can begin in the second or third decade of life or earlier, with seizures ranging from rare to very frequent, often resistant to polytherapy. Most patients present with partial seizures, exceptionally with status epilepticus. ${ }^{5}$ Mental retardation, usually absent or mild, can also be severe and associated with neurological deficits and dysmorphic features. ${ }^{25} 26$

Dubeau et $_{\mathrm{al}} \mathrm{l}^{5}$ divided $\mathrm{PNH}$ patients according to the type of the heterotopic grey matter into two groups: the first included 18 patients showing $\mathrm{PNH}$ alone, the second comprised 11 patients with PNH and subcortical nodules. However, reviewing the neuroradiological features described in those patients, we observed that some cases with PNH alone also showed other malformations (that is, dysplasia of the motor cortex, cerebellar and corpus callosum hypoplasia, mega cisterna magna), whereas most patients with $\mathrm{PNH}$ associated with subcortical nodules also included focal cortical involvement (that is, cortical dysplasia, microgyria, schizencephaly). Although prenatal history, sex, age at seizure onset, and epilepsy did not significantly differ in the two groups, patients with $\mathrm{PNH}$ and subcortical nodules tended to have higher prevalence of epilepsy, developmental delay, and neurological deficit.

Heterogeneous EEG findings have also been reported in PNH patients with focal abnormalities consistent with the location of periventricular nodules, ${ }^{17}$ but also generalised discharges mimicking primary generalised epilepsy have been described. ${ }^{24}{ }^{27}$ Battaglia et al ${ }^{17}$ observed that PNH patients showed a photic driving response and suggested that this may be an indication of some neuronal hyperexcitability in posterior cortical regions close to or overlying the PNH.

Few reports have described the long term prognosis of epilepsy in $\mathrm{MCD}^{22}$ and little is known about the outcome of patients with $\mathrm{PNH}$, especially regarding the epilepsy course. Like most of the literature cases, our PNH patients showed a heterogeneous clinical picture: patients with drug responsive epilepsy and normal intelligence as compared with patients with catastrophic epilepsy and mental retardation. Dividing our patients according to the presence of only periventricular nodules (simple) and periventricular nodules associated with other cerebral and/or cortical abnormalities (plus), we identified two electroclinical groups, homogeneous in features and with a distinct outcome. Although observation time of simple and plus patients differed because of the different age at seizure onset, seizure frequency at onset and during life and clinical features of two groups were significantly distinct. Simple PNH patients have a comparatively "benign" course with seizures beginning during the second decade of life and rare in frequency at onset. During life, seizures may temporarily increase, but without reaching a high frequency (never daily) and usually disappear or become very rare. In contrast, the course and outcome of epilepsy is significantly "worse" in plus patients who have a significantly $(\mathrm{p}<0.001)$ earlier onset (usually first decade) of seizures with significantly $(p<0.002)$ higher frequency (daily-monthly). In only two patients of eight in this series, seizures progressively disappeared after many years. In addition, simple patients present epilepsy with usually partial seizures with secondary generalisation and drug responsive, without mental retardation. EEG may be normal or with focal abnormalities. Plus cases also have mental retardation $(p=0.041)$ associated with partial seizures, often accompanied with sudden drops $(p<0.001)$ and resistance to therapy. EEG shows focal but also bisynchronous abnormalities, according to clinical evidence of drops. ${ }^{28}$ In none of the patients was there evidence of photic driving on the EEG: the prevalent localisation of nodules in our series along the temporal and frontal horns may justify this lack of response, compared with other literature cases. ${ }^{17}$ In our patients, MRI disclosed a prevalent localisation of nodules along the walls of right lateral ventricle (9 of 16 patients). Raymond et al were the first to report this observation and suggested that right sided neuroblasts may complete migration slightly later than those on the left. ${ }^{24}$ By contrast, other authors ${ }^{17}$ emphasised the particular susceptibility of the right paratrigonal region to ischaemic insults during the early ontogenetic period. This hypothesis seems to be confirmed by the observation that, in our patients, the prevalent localisation of nodules along the walls of the right lateral ventricle is especially evident in plus cases. In these cases, the presence of periventricular nodules, more often on the right side and associated with polymicrogyria or schizencephaly, may be secondary to prenatal risk factors, intrauterine hypoxic-ischaemic injuries affecting the late phases of cortical development, ${ }^{29}$ confirming the particular susceptibility of the right region to hypoxic-ischaemic insults.

In conclusion, the impressive advances in neuroimaging techniques and increased understanding of the role of genetics in controlling the development of the central nervous system have transformed our knowledge of MCD. In depth evaluation of the clinical features and long term follow up of these patients has often been neglected. Our work is a retrospective study yielding some insight into the long term follow up and course of epilepsy in PNH patients. We identified two groups of PNH patients (simple and plus) with different electroclinical and neuroradiological features with homogeneous peculiarities and different prognosis. In particular, other types of cortical or cerebral malformations, in addition to periventricular nodules, worsen the prognosis.

\section{ACKNOWLEDGEMENTS}

We are indebted to the patients for participating in this study. We thank Elena Zoni and Massimo Armaroli for their help in manuscript editing, Anne Collins for revising the English. This paper was presented as a poster at the European Congress on Epileptology Madrid 6-10 October 2002.

\section{Authors' affiliations}

G d'Orsi, P Tinuper, F Bisulli, A Zaniboni, R Riva, A Baruzzi, Department of Neurological Sciences, University of Bologna, Bologna, Italy

B Bernardi, G Rubboli, R Michelucci, L Volpi, C A Tassinari, Department of Neurosciences, Bellaria Hospital, Bologna, Italy

Competing interests: none declared

\section{REFERENCES}

1 Friede RL. Developmental neuropathology, 2nd edn. New York: SprinterVerlag, 1989.

2 Sarnat HB. Cerebral dysplasias as expressions of altered maturational processes. Can J Neurol Sci 1991; 18:196-204.

3 Barkovich AJ, Kuzniecky RI, Dobyns WB, et al. A classification scheme for malformations of cortical development. Neuropediatrics 1996;27:59-63.

4 Sidman RL, Rakic P. Neuronal migration, with special reference to developing human brain: a review. Brain Res 1973;62:1-35.

5 Dubeau $F$, Tampieri D, Lee N, et al. Periventricular and subcortical nodular heterotopia. A study of 33 patients. Brain 1995; 118:1273-87.

6 Kernohan JW. Cortical anomalies, ventricular heterotopias and occlusion of the acqueduct of Sylvius. Arch Neurol Psychiatr 1930;23:460-80. 
7 Tungel C. Ein Fall von Neubildung grauer Hirnsubstanz. Virchows Arch Pathol Anat 1859;16:166-8

8 Meschede F. Uber Neubildung graver Hiensubstanz in den Wandungen der Seiten-Ventrikel und uber eine bisher nicht beschriebene, durch Hyperplasie graver Corticalsulbstanz bedingte Structur-Anomalie der Hirnrinde. Psychiat Psychisch Gerichtl Med 1864;1:481-505.

9 Meschede F. Ein neure Fall von abnormen Einlagerungen grauer Hirnsubstanz innerhalb der medullarsubstanz des grossen gehirns. Virchows Arch 1866;37:567-70

10 Virchow R. Heterotopie der grauen Sunstanz . Virchows Arch 1867;38:138-42

11 Mattel M. Ein Fall von Heterotopie der grauen Substanz in den beidein Hemispharen des Grosshirns. Arch Psychiat Nervkrankh 1893;25:124-36.

12 Layton DD. Heterotopic cerebral gray matter as an epileptogenic focus. J Neuropathol Exp Neurol 1962;21:244-9.

13 Bergeron RT. Pneumographic demonstration of subependymal heterotopic cortical gray matter in children. Am J Roentgenol Radium Ther Nucl Med 1967;101:168-77.

14 Oda T, Nagai Y, Fujimoto S, et al. Hereditary nodular heterotopia accompanied by mega cisterna magna. Am J Med Genet 1994;47:268-71.

15 Bargallo N, Puerto B, De Juan C, et al. Hereditary subependymal heterotopia associated with mega cisterna magna: antenatal diagnosis with magnetic resonance imaging. Ultrasound Obstet Gynecol 2002;20:86-9.

16 Mitchell LA, Simon EM, Filly A, et al. Antenatal diagnosis of subependymal heterotopia. Am J Neuroradiol 2000;21:296-300.

17 Battaglia G, Granata T, Farina L, et al. Periventricular nodular heterotopia: epileptogenic findings. Epilepsia 1997;38:1173-82.

18 Barkovic AJ, Kuzniecky RI, Jackson GD, et al. Classification system for malformations of cortical development. Neurology 2001;57:2168-78.

19 Barkovic AJ. Magnetic resonance imaging: role in the understanding of cerebral malformations. Brain Dev 2002;24:2-12.
20 Barkovich AJ, Kuzniecky RI, Dobyns WB. Radiologic classification of malformations of cortical development. Curr Opin Neurol 2001;14:145-9.

21 Guerrini R, Genton P, Bureau M, et al. Multilobar polymicrogyria, intractable drop attack seizures, and sleep-related electrical status epilepticus. Neurology 1998;51:504-12

22 Dravet C, Guerrini R, Mancini J, et al. Different outcome of epilepsy due to cortical dysplastic lesions. In: Guerrini R, Canapicu R, Zifkin BG, et al, eds. Dysplasias of cerebral cortex and epilepsy. Philadelphia: Lippincott-Raven, 1996:323-8.

23 Borjeson M, Forssman H, Lehmann O. An X-linked, recessively inherited syndrome characterized by grave mental deficiency, epilepsy, and endocrine disorder. Acta Med Scand 1962;171:13.

24 Raymond AA, Fish DR, Stevens JM, et al. Subependymal heterotopia: a distinct neuronal migration disorder associated with epilepsy. J Neurol Neurosurg Psychiatry 1994;57:1195-202.

25 Dobyns WB, Guerrini R, Czapansky-Beilman DK, et al. Bilateral periventricular nodular heterotopia (BPNH) with mental retardation and syndactyly in boys: a new X-linked mental retardation syndrome. Neurology 1997;49:1042-7.

26 Guerrini R, Dobyns WB. Bilateral periventricular nodular heterotopia with mental retardation and frontonasal malformation. Neurology 1998;51:499-503.

27 Giza CC, Kuratani JD, Saukar R. Periventricular nodular heterotopia and chilhood absence epilepsy. Pediatr Neurol 1999;20:315-18.

28 Tinuper P, Cerullo A, Marini C, et al. Epileptic drop attacks in partial epilepsy: clinical features, evolution, and prognosis. I Neurol Neurosurg Psychiatry 1998:64:231-7.

29 Cohen M, Roessmann V. In utero brain damage: relationship of gestational age to pathological consequences. Dev Med Child Neurol 1994;36:263-8. 